\section{A highly permeable and selective zeolitic imidazolate framework ZIF-95 membrane for $\mathrm{H}_{2} / \mathrm{CO}_{2}$ separation $\dagger$}

\author{
Aisheng Huang, ${ }^{a} a$ Yifei Chen, ${ }^{b}$ Nanyi Wang, ${ }^{c}$ Zhongqiao Hu, ${ }^{b}$ Jianwen Jiang ${ }^{b}$ and \\ Jürgen Caro*c
}

Received 6th August 2012, Accepted 19th September 2012

DOI: $10.1039 / \mathrm{c} 2 \mathrm{cc} 35691 \mathrm{k}$

Making use of the preferred adsorption affinity and capacity to $\mathrm{CO}_{2}$ as well as the highly porous structure with huge cavities of $2.4 \mathrm{~nm}$, a highly permeable and selective ZIF-95 molecular sieve membrane was developed for the separation of $\mathrm{H}_{2}$ from $\mathrm{CO}_{2}$.

As a clean and efficient energy source related to global climate change, energy security, and reduction of local air pollution, the demand for hydrogen has been increasingly growing in recent years. ${ }^{1}$ The majority of hydrogen is produced via steammethane reforming (SMR) followed by water-gas shift (WGS). The resulting gas mixture is mainly composed of $\mathrm{H}_{2}$ and $\mathrm{CO}_{2}$ which are principally separated by pressure swing adsorption (PSA). ${ }^{2}$ In comparison with conventional separation methods like PSA, membrane-based separation has been considered to be the most promising alternative because of its low energy consumption, ease of operation, and cost effectiveness. ${ }^{3}$ Since organic polymer membranes suffer from instability problems in contact with solvents or at high temperatures, inorganic membranes are more promising under harsh separation conditions. ${ }^{4}$ So far, $\mathrm{H}_{2}$-permselective inorganic membranes, typically dense Pd-based metal membranes, ${ }^{5}$ microporous silica membranes, ${ }^{6}$ carbon membranes, ${ }^{7}$ and zeolite membranes ${ }^{8-11}$ have been developed for the separation of $\mathrm{H}_{2}$ from $\mathrm{CO}_{2}$. The Pd membranes display high $\mathrm{H}_{2}$ selectivity and $\mathrm{H}_{2}$ permeance at high temperature, but they easily degrade in contact with $\mathrm{CO}$ or $\mathrm{H}_{2} \mathrm{~S} .{ }^{6}$ In addition, the high $\mathrm{Pd}$ cost is another bottleneck for the wide application of Pd-based membranes. The microporous silica membranes have amazing $\mathrm{H}_{2}$ selectivity over other small molecular gases, ${ }^{7}$ but suffer from instability if traces of steam are present. ${ }^{12}$ Carbon membranes are too fragile to be used in practice. ${ }^{13}$ Due to intercrystalline defects and relatively large pore sizes in comparison with the kinetic

\footnotetext{
${ }^{a}$ Institute of New Energy Technology, Ningbo Institute of Material Technology and Engineering, CAS, 519 Zhuangshi Road,

315201 Ningbo, P. R. China. E-mail: huangaisheng@nimte.ac.cn

${ }^{b}$ Department of Chemical and Biomolecular Engineering,

National University of Singapore, 117576, Singapore

${ }^{c}$ Institute of Physical Chemistry and Electrochemistry,

Leibniz University Hannover, Callinstraße 3-3A, D-30167 Hannover, Germany.E-mail: juergen.caro@pci.uni-hannover.de;

Tel: + 49-511-762 3185

$\dagger$ Electronic supplementary information (ESI) available: Experimental details, SEM, XRD, simulation study of gas isotherms, measurement equipment and gas permeances. See DOI: 10.1039/c2cc35691k
}

diameters of $\mathrm{H}_{2}(0.29 \mathrm{~nm})$ and $\mathrm{CO}_{2}(0.33 \mathrm{~nm})$, the zeolite membranes usually show low $\mathrm{H}_{2} / \mathrm{CO}_{2}$ selectivity. ${ }^{8-11}$ Therefore, the development of thermally and hydrothermally stable microporous membranes with high $\mathrm{H}_{2}$ permselectivity is highly desired.

Microporous metal-organic frameworks (MOFs) have attracted intense attention as fascinating candidates for the fabrication of membranes/films due to their highly diversified pore structures and pore sizes as well as specific adsorption affinities. ${ }^{14-17}$ In particular, zeolitic imidazolate frameworks (ZIFs) have emerged as a novel type of crystalline porous material for the preparation of superior molecular sieve membranes attributed to their zeolite-like properties such as permanent porosity, uniform pore sizes, and exceptional thermal and chemical stability. ${ }^{18,19}$ Very recently, we have developed a series of supported ZIF membranes, including SOD-type ZIF-7, ${ }^{20} \mathrm{ZIF}-8^{21}$ and ZIF- $90^{22,23}$ as well as LTAtype ZIF-22. ${ }^{24}$ These ZIF membranes have shown promising separation selectivities, but the permeances are relatively low for practical applications. Therefore, the challenge is to prepare ZIF membranes with high permeance, while maintaining their high separation selectivity. So far, there have been only a few reports on highly permeable ZIF membranes. ${ }^{25}$

Recently, Yaghi and co-workers have developed a novel POZ topology porous ZIF called ZIF-95 with an unprecedented structural complexity through solvothermal reaction of zinc(II) salt and 5-chlorobenzimidazole (cbIM). ${ }^{26}$ It is reported that ZIF-95 is not only highly thermally stable up to $500{ }^{\circ} \mathrm{C}$ but also shows permanent microporosity with constricted windows $(\sim 0.37 \mathrm{~nm})$ and huge cavities $(2.4 \mathrm{~nm})$. Especially, ZIF-95 shows a high affinity and capacity for $\mathrm{CO}_{2}$ adsorption, which can be promising for $\mathrm{CO}_{2}$ capture. ${ }^{26}$ Actually, various MOFs have been proposed as promising candidates for $\mathrm{CO}_{2}$ adsorption, capture and storage. ${ }^{27-30}$ To the best of our knowledge, there is no report on the fabrication of a $\mathrm{CO}_{2}$ captive $\mathrm{MOF}$ membrane for the separation of $\mathrm{H}_{2}-\mathrm{CO}_{2}$ mixtures. In the present work, we report synthesis and gas separation performance of a highly permeable and selective ZIF-95 molecular sieve membrane as a $\mathrm{CO}_{2}$ captor for the separation of $\mathrm{H}_{2} / \mathrm{CO}_{2}$ at high temperatures. For ZIF structures with huge cavities interconnected by small windows, the strongly adsorbed component is immobilized in the big cavities and permeation becomes diffusion-controlled in favor of the highly mobile component. 
It can be expected, therefore, that a ZIF-95 can be fabricated as a membrane for the separation of $\mathrm{H}_{2}-\mathrm{CO}_{2}$ mixtures since $\mathrm{CO}_{2}$ is preferentially adsorbed, and $\mathrm{H}_{2}$ can pass through the membrane, as shown in Fig. S1 (ESI $\dagger$ ).

After solvothermal reaction for 3 days at $120{ }^{\circ} \mathrm{C}$, the surface of an APTES-modified asymmetric macroporous $\alpha-\mathrm{Al}_{2} \mathrm{O}_{3}$ disk has been completely covered by typically tetragon-shaped ZIF-95 crystals (Fig. S2a-c, ESI $\dagger$ ). ${ }^{26}$ Unlike the conventional MOF or zeolite membranes growth, the tetragonal plates do not grow layer-by-layer, but interlock to form a novel membrane structure like folded filters (circle in Fig. S2c, ESI $\dagger$ ). Such a large corrugation of the membrane layer can increase the effective surface for permeation and hence promote a high gas permeance. From the cross-sectional view shown in Fig. S2d (ESI $\dagger$ ), it can be seen that the ZIF-95 layer is well intergrown as a continuous membrane with a thickness of about $30 \mu \mathrm{m}$. Similar to our previous reports, ${ }^{22,24}$ APTES modification of alumina supports before solvothermal synthesis is helpful in forming a continuous layer. No continuous ZIF-95 layer can be formed on the nonAPTES-modified $\alpha-\mathrm{Al}_{2} \mathrm{O}_{3}$ disk by in situ growth (Fig. S3, ESI $\dagger$ ).

After on-stream activation at $325{ }^{\circ} \mathrm{C}$ using an equimolar $\mathrm{H}_{2}-\mathrm{CO}_{2}$ mixture in the Wicke-Kallenbach permeation apparatus (Fig. S4, ESI $\dagger$ ), the volumetric flow rates of the single gases $\mathrm{H}_{2}, \mathrm{CO}_{2}, \mathrm{~N}_{2}, \mathrm{CH}_{4}$ and $\mathrm{C}_{3} \mathrm{H}_{8}$ as well as the equimolar binary mixtures of $\mathrm{H}_{2}$ with $\mathrm{CO}_{2}, \mathrm{~N}_{2}, \mathrm{CH}_{4}$ and $\mathrm{C}_{3} \mathrm{H}_{8}$ were measured through the activated ZIF-95 membrane by using the Wicke-Kallenbach technique. The permeances and separation factors are summarized in Table S1 (ESI $\dagger$ ). Fig. 1 shows the permeances of the single gases through the activated ZIF-95 membrane as a function of the kinetic diameters of the permeating molecules. As shown in Fig. 1 and Table $\mathrm{S} 1$ (ESI $\dagger$ ), $\mathrm{H}_{2}$ has the highest permeance of $2.46 \times 10^{-6} \mathrm{~mol} \mathrm{~m}^{-2} \mathrm{~s}^{-1} \mathrm{~Pa}^{-1}$ due to its small kinetic diameter of $0.29 \mathrm{~nm}$. The single gas permeances through the ZIF-95 membrane follow the order: $\mathrm{H}_{2}>\mathrm{N}_{2}>$ $\mathrm{CH}_{4}>\mathrm{CO}_{2}>\mathrm{C}_{3} \mathrm{H}_{8}$, which mainly corresponds to their kinetic diameters with the exception of $\mathrm{CO}_{2}$. As reported previously, ${ }^{26}$ ZIF-95 has a high affinity and capacity for $\mathrm{CO}_{2}$ adsorption due to strong quadrupolar interactions of carbon with nitrogen atoms present in the linkers of ZIF-95, leading to a strong adsorption interaction but lowering the diffusional mobility, which results in the end in a lower $\mathrm{CO}_{2}$ permeance

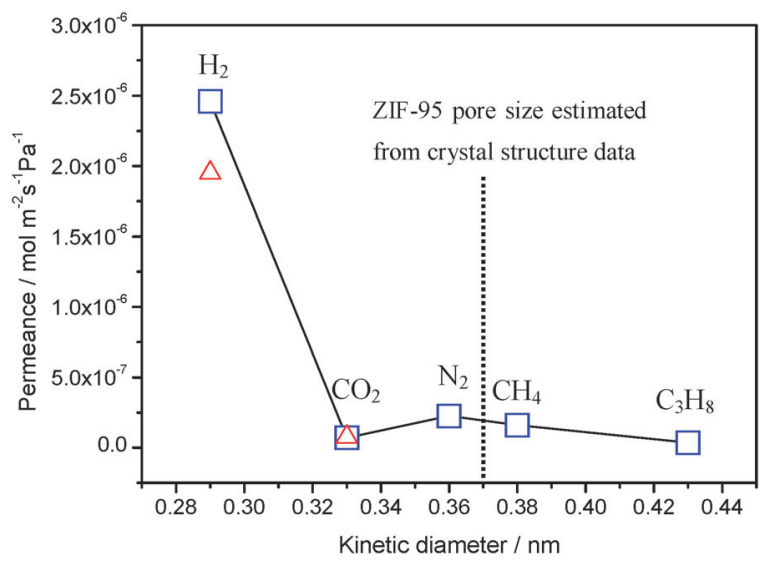

Fig. 1 Single gas permeances of the ZIF-95 membrane as a function of the kinetic diameter at $325^{\circ} \mathrm{C}$. The triangles show the permeances of $\mathrm{H}_{2}$ and $\mathrm{CO}_{2}$ in an equivalent binary mixture. than found for other small molecules like $\mathrm{N}_{2}$ and $\mathrm{CH}_{4}$. The strong adsorption affinity of ZIF-95 to $\mathrm{CO}_{2}$ is also confirmed by a simulation study of the gas adsorption isotherms which coincide with the measured ones (Fig. S5, ESI $\dagger$ ). It should be noted that similar to the reported $\mathrm{MOF}$ membranes ${ }^{20-24}$ or MOF crystals, ${ }^{31,32}$ molecules like $\mathrm{CH}_{4}$ and $\mathrm{C}_{3} \mathrm{H}_{8}$ with a kinetic diameter larger than the crystallographic pore size of ZIF-95 can pass through the membrane due to the well-known lattice flexibility of MOFs. The ideal separation factors of $\mathrm{H}_{2}$ from $\mathrm{CO}_{2}, \mathrm{~N}_{2}, \mathrm{CH}_{4}$ and $\mathrm{C}_{3} \mathrm{H}_{8}$ are $34.9,10.8,15.3$ and 66.8, respectively, suggesting that the ZIF-95 membrane displays a high hydrogen permselectivity.

The performance of the ZIF-95 membrane was confirmed by the separation of equimolar gas mixtures at $325{ }^{\circ} \mathrm{C}$ and 1 bar. For the $1: 1$ binary mixtures, the mixture separation factor for $\mathrm{H}_{2} / \mathrm{CO}_{2}$ is 25.7 , which by far exceeds the corresponding Knudsen coefficient (4.7). According to the simulated adsorption isotherms of the equimolar $\mathrm{H}_{2}-\mathrm{CO}_{2}$ mixture in ZIF-95 at $25{ }^{\circ} \mathrm{C}$ (Fig. S6, ESI $\dagger$ ), $\mathrm{CO}_{2}$ is predominantly adsorbed over $\mathrm{H}_{2}$ in the entire pressure range because $\mathrm{CO}_{2}$ has a far stronger interaction with ZIF-95 than $\mathrm{H}_{2}$ (Fig. 2), which is helpful in trapping $\mathrm{CO}_{2}$, and therefore, enhances the $\mathrm{H}_{2} / \mathrm{CO}_{2}$ selectivity. Compared with the $\mathrm{H}_{2}$ single gas permeance, the $\mathrm{H}_{2}$ permeance from $\mathrm{H}_{2}-\mathrm{CO}_{2}$ mixtures shows a slight reduction, with $\mathrm{H}_{2}$ permeances of $1.95 \times 10^{-6} \mathrm{~mol} \mathrm{~m}^{-2} \mathrm{~s}^{-1} \mathrm{~Pa}^{-1}$, indicating that the faster diffusing $\mathrm{H}_{2}$ molecules are inhibited by the stronger adsorbed $\mathrm{CO}_{2}$ molecules. For the $1: 1$ binary mixtures, the mixture separation factors of $\mathrm{H}_{2} / \mathrm{N}_{2}, \mathrm{H}_{2} / \mathrm{CH}_{4}$ and $\mathrm{H}_{2} / \mathrm{C}_{3} \mathrm{H}_{8}$ are 10.2, 11.0 and 59.7, which again exceed the corresponding Knudsen coefficients (3.7, 2.8 and 4.7). To the best of our knowledge, our ZIF-95 membrane shows by far the highest $\mathrm{H}_{2} / \mathrm{CO}_{2}$ selectivity for MOF and zeolite membranes (Table S2, ESI $\dagger$ ). Further, compared with literature data of $\mathrm{H}_{2}$ permeances on MOF membranes, the ZIF-95 membrane developed in this study shows a superior $\mathrm{H}_{2}$ permeance, and also exceeds the Robeson "upper-bound" for polymeric membranes (Fig. 3). The obtained high $\mathrm{H}_{2}$ permeance of the ZIF-95 membrane is attributed not only to its highly porous structure with huge cavities $(2.4 \mathrm{~nm})$ and large windows $(0.37 \mathrm{~nm})$, but also to the novel "folded filters" membrane structure

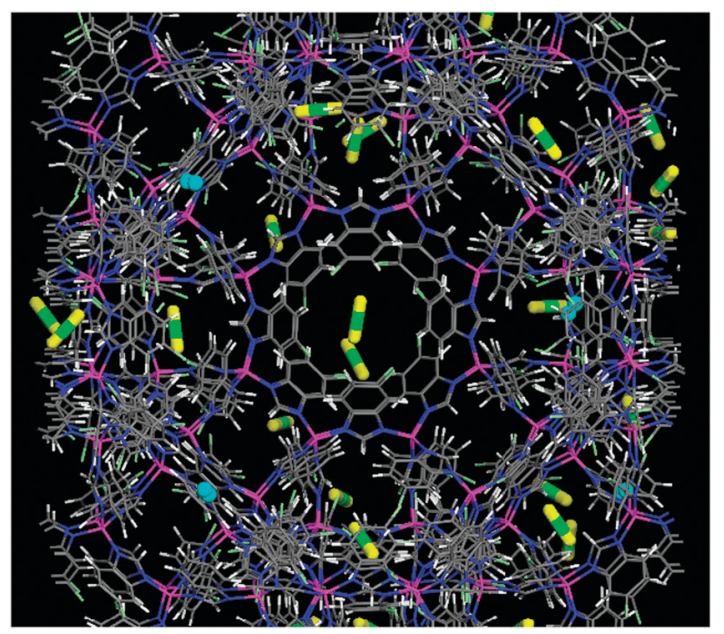

Fig. 2 Snapshot of adsorbed $\mathrm{CO}_{2}$ and $\mathrm{H}_{2}$ molecules in the ZIF-95 cages at $25{ }^{\circ} \mathrm{C}$ and $100 \mathrm{kPa}$. $\mathrm{CO}_{2}$ : yellow-green and $\mathrm{H}_{2}$ : cyan. 


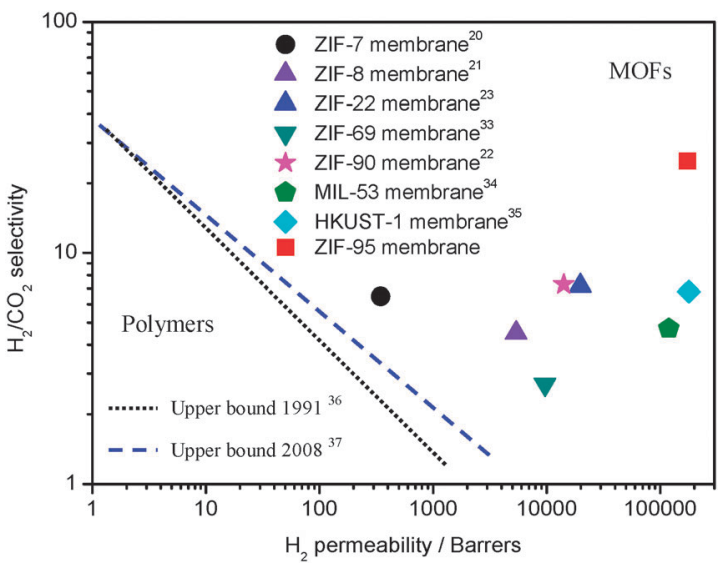

Fig. $3 \mathrm{H}_{2} / \mathrm{CO}_{2}$ selectivity versus $\mathrm{H}_{2}$ permeability for polymeric membranes and MOF membranes. The upper bound lines for polymeric membranes are drawn based on ref. 36 and 37.

which is helpful in reducing the flow resistance of gas transport. It is found that APTES-modification of the supports is helpful in eliminating the influence of the surface chemistry and thus enhances the reproducibility of the membrane preparation (Table S3, ESI $\dagger$ ).

Fig. S7 (ESI $\dagger$ ) shows mixed gas permeances and the $\mathrm{H}_{2} / \mathrm{CO}_{2}$ selectivity of the ZIF-95 membrane as a function of the operating temperatures at 1 bar. When the temperature is increased from 25 to $325^{\circ} \mathrm{C}$, the $\mathrm{H}_{2}$ permeance increases from $5.00 \times 10^{-7}$ to $1.96 \times 10^{-6} \mathrm{~mol} \mathrm{~m}^{-2} \mathrm{~s}^{-1} \mathrm{~Pa}^{-1}$ and the $\mathrm{CO}_{2}$ permeance slightly increases from $5.91 \times 10^{-8}$ to $7.64 \times$ $10^{-8} \mathrm{~mol} \mathrm{~m}^{-2} \mathrm{~s}^{-1} \mathrm{~Pa}^{-1}$, resulting in an observable increase in the $\mathrm{H}_{2}-\mathrm{CO}_{2}$ mixture separation factor from 8.5 to 25.7. This phenomenon can be explained by the adsorption-diffusion model. As mentioned above, ZIF-95 has a high affinity and capacity for $\mathrm{CO}_{2}$ adsorption. Therefore, at low temperature mainly $\mathrm{CO}_{2}$ is adsorbed in the ZIF-95 pores (Fig. S8, ESI $\dagger$ ), thus blocking the diffusion of the rarely adsorbed and highly mobile $\mathrm{H}_{2}$ (Fig. 2). As the temperature increases, less $\mathrm{CO}_{2}$ becomes adsorbed and thus more $\mathrm{H}_{2}$ can diffuse in the resulting free volume, leading to a large enhancement of the $\mathrm{H}_{2}$ permeance, and consequently selectivity. The ZIF-95 membrane has been tested at $325^{\circ} \mathrm{C}$ for $24 \mathrm{~h}$, and it still retains its high separation performances with a $\mathrm{H}_{2}$ permeance of about $1.94 \times 10^{-6} \mathrm{~mol} \mathrm{~m}^{-2} \mathrm{~s}^{-1} \mathrm{~Pa}^{-1}$ and a $\mathrm{H}_{2} / \mathrm{CO}_{2}$ selectivity of 25.6 (Fig. S9, ESI $\dagger$ ). XRD analysis shows that all peaks of the spent ZIF-95 membrane match well with those of the as-prepared ZIF-95 membrane (Fig. S10, ESI $\dagger$ ), indicating that the ZIF-95 membrane has a high thermal stability. Further, the ZIF-95 membranes show a very good stability in the presence of steam, and both the $\mathrm{H}_{2}$ permeance and the $\mathrm{H}_{2} / \mathrm{CO}_{2}$ selectivity are unchanged for $24 \mathrm{~h}$ (Fig. S11, ESI $\dagger$ ). This hydrothermal stability combined with a high thermal stability indicates that the permselective ZIF-95 membrane is of promising importance for hydrogen production.

In conclusion, in the present work we have designed and prepared a highly permselective ZIF-95 molecular sieve membrane for the separation of $\mathrm{H}_{2}$ from $\mathrm{CO}_{2}$. For binary mixtures at $325^{\circ} \mathrm{C}$ and 1 bar, the mixture separation factors of $\mathrm{H}_{2} / \mathrm{CO}_{2}, \mathrm{H}_{2} / \mathrm{N}_{2}$, $\mathrm{H}_{2} / \mathrm{CH}_{4}$ and $\mathrm{H}_{2} / \mathrm{C}_{3} \mathrm{H}_{8}$ were 25.7, 10.2, 11.0 and 59.7, respectively, which by far exceed the corresponding Knudsen coefficients. The ZIF-95 membrane also displayed high $\mathrm{H}_{2}$ permeances of about
$1.9 \times 10^{-6} \mathrm{~mol} \mathrm{~m}^{-2} \mathrm{~s}^{-1} \mathrm{~Pa}^{-1}$ due to its highly porous structure with huge cavities as well as a novel "folded filters" membrane structure. Further, the ZIF-95 membrane shows a high thermal stability up to at least $325^{\circ} \mathrm{C}$ and hydrothermal stability in steam, thus offering a potential application in hydrogen production.

Financial support from EU CARENA (FP7-NMP-2010LARGE-4, No. 263007), Starting Research Fund of Team Talent from NIMTE (Y20808RA05), and the National Research Foundation of Singapore (R-279-000-261-281) is acknowledged.

\section{Notes and references}

1 S. Dunn, Int. J. Hydrogen Energy, 2002, 27, 235.

2 J. R. Rostrup-Nielsen and T. Rostrup-Nielsen, CATTECH, 2002, 6, 150 .

3 N. W. Ockwig and T. M. Nenoff, Chem. Rev., 2007, 107, 4078.

4 G. Q. Lu, J. C. Diniz da Costa, M. Duke, S. Giessler, R. Socolow, R. H. Williams and T. Kreutz, J. Colloid Interface Sci., 2007, 314, 589.

5 S. Uemiya, T. Matsuda and E. Kikuchi, J. Membr. Sci., 1991, 56, 315.

6 R. M. de Vos and H. Verweij, Science, 1998, 279, 1710.

7 M. B. Shiflett and H. C. Foley, Science, 1999, 285, 1902.

8 M. Hong, S. Li, J. L. Falconer and R. D. Noble, J. Membr. Sci., 2008, 307, 277.

9 M. Kanezashi, J. O'Brien-Abraham, Y. S. Lin and K. Suzuki, AIChE J., 2008, 54, 1478.

$10 \mathrm{~J}$. van den Bergh, A. Tihaya and F. Kapteijn, Microporous Mesoporous Mater., 2010, 132, 137.

11 A. Huang and J. Caro, Chem. Commun., 2010, 46, 7748.

12 Y. S. Lin, I. Kumakiri, B. N. Nair and H. Alsyouri, Sep. Purif. Methods, 2002, 31, 229.

13 A. F. Ismail and L. I. B. David, J. Membr. Sci., 2001, 193, 1.

14 R. Ranjan and M. Tsapatsis, Chem. Mater., 2009, 21, 4920.

15 S. Hermes, F. Schroder, R. Chelmowski, C. Woll and R. A. Fischer, J. Am. Chem. Soc., 2005, 127, 13744.

16 J. Caro, Curr. Opin. Chem. Eng., 2012, 1, 77.

17 A. Bétard and R. A. Fischer, Chem. Rev., 2012, 112, 1055.

18 K. S. Park, Z. Ni, A. P. Côté, J. Y. Choi, R. Huang, F. J. UribeRomo, H. K. Chae, M. O'Keeffe and O. M. Yaghi, Proc. Natl. Acad. Sci. U. S. A., 2006, 103, 10186.

19 A. Phan, C. J. Doonan, F. J. Uribe-romo, C. B. Knobler, M. O'Keeffe and O. M. Yaghi, Acc. Chem. Res., 2009, 43, 58.

20 Y. Li, F. Liang, H. Bux, A. Feldhoff, W. Yang and J. Caro, Angew. Chem., Int. Ed., 2010, 49, 548.

21 H. Bux, F. Liang, Y. Li, J. Cravillon, M. Wiebcke and J. Caro, J. Am. Chem. Soc., 2009, 131, 16000.

22 A. Huang, W. Dou and J. Caro, J. Am. Chem. Soc., 2010, 132, 15562.

23 A. Huang, H. Bux, F. Steinbach and J. Caro, Angew. Chem., Int. Ed., 2010, 49, 4958.

24 A. Huang and J. Caro, Angew. Chem., Int. Ed., 2011, 50, 4979.

25 S. R. Venna and M. A. Carreon, J. Am. Chem. Soc., 2010, 132, 76.

26 B. Wang, A. P. Côté, H. Furukawa, M. O'Keeffe and O. M. Yaghi, Nature, 2008, 453, 207.

27 R. Krishna and J. M. van Baten, Phys. Chem. Chem. Phys., 2011, 13, 10593.

28 D. M. d'Alessandro, B. Smit and J. R. Long, Angew. Chem., Int. Ed., 2010, 49, 6058.

29 J.-R. Li, Y. Ma, M. C. McCarthy, J. Sculley, J. Yu, H.-K. Jeong, P. B. Balbuena and H. C. Zhou, Coord. Chem. Rev., 2011, 255, 1791.

30 Q. Wang, J. Luo, Z. Zhong and A. Borgna, Energy Environ. Sci., $2011,4,42$.

31 J. van den Bergh, C. Gücüyener, E. A. Pidko, E. J. M. Hensen, J. Gascon and F. Kapteijn, Chem.-Eur. J., 2011, 17, 8832.

32 S. Aguado, G. Bergeret, M. P. Titus, V. Moizan, C. Nieto-Draghi, N. Bats and D. Farrusseng, New J. Chem., 2011, 35, 499.

33 Y. Liu, E. Hu, E. A. Khan and Z. Lai, J. Membr. Sci., 2010, 353, 36.

34 Y. Hu, X. Dong, J. Nan, W. Jin, X. Ren, N. Xu and Y. M. Lee, Chem. Commun., 2011, 47, 737.

35 H. Guo, G. Zhu, I. J. Hewitt and S. Qiu, J. Am. Chem. Soc., 2009, 131, 1646.

36 L. M. Robeson, J. Membr. Sci., 1991, 62, 165.

37 L. M. Robeson, J. Membr. Sci., 2008, 320, 390. 